\title{
LER E ESCREVER COMO POSSIBILIDADE DE UMA RELAÇÃO INFANTIL COM O TEMPO
}

Betina Schuler ${ }^{1}$

\section{RESUMO}

Este artigo problematiza como as crianças vêm se relacionando com o tempo, por meio do exame de cadernos escolares datados de 1923 a 2016, recolhidos no Estado do Rio Grande do Sul, e a partir do exame de oficinas realizadas com alunos e professores em escolas públicas. Destaca-se, arquegenealogicamente, o deslocamento de práticas de escrita e de leitura que tematizavam a vida e a morte para uma contagem cronológica do tempo, em que a infância vem sendo narrada como promessa de futuro e, mais contemporaneamente, atravessada pelos sintomas da aceleração, do desempenho e da instrumentalidade utilitária. Opta-se, assim, por tomar a infância como uma condição da experiência, potencializada por escritas e leituras que poderiam tornar possíveis outros modos de pensamento e existência.

Palavras-chave: tempo, infancia, práticas de escrita e leitura.

\section{LEER Y ESCRIBIR COMO UNA POSIBILIDAD DE RELACION DE LA INFANCIA CON EL TIEMPO}

\footnotetext{
${ }^{1}$ Universidade do Vale do Rio dos Sinos (Unisinos), São Leopoldo/RS, Brasil.
} 


\section{RESUMEN}

Este articulo problematiza cómo los niños vienen relacionándose con el tiempo, a través del examen de cuadernos escolares datados de 1923 a 2016, recogidos en el Estado de Rio Grande do Sul/Brasil, y a partir del examen de talleres realizados con alumnos y profesores en escuelas públicas. Se destaca, arquegenealógicamente, el desplazamiento de prácticas de lectura y escritura que tematizaban la vida y la muerte como relato cronológico del tiempo, en donde la infancia se narra cómo promesa de futuro y, más contemporáneamente, atravesada por los síntomas de la aceleración, el desempeño y la instrumentalidad utilitaria. Se opta, así, por tomar la infancia como una condición de la experiencia, potencializada por lecturas y escrituras que podrían hacer posible otros modos de pensamiento y existencia.

Palabras clave: tiempo, infancia, prácticas de lectura y escritura.

\section{READING AND WRITING AS A POSSIBILITY OF AN INFANT RELATIONSHIP WITH TIME}

\section{ABSTRACT}

This paper problematizes the way in which children have related with time, by examining school notebooks dated from 1923 to 2016 collected in the State of Rio Grande do Sul, in the south of Brazil, and workshops held with students and teachers in public schools. Arche-genealogically, it highlights the displacement of writing and reading practices that addressed life and death to a focus on a chronological time counting, in which childhood has been both narrated as a promise of future and, more contemporarily, crossed by symptoms of acceleration, performance and utilitarian instrumentality. Thus, it regards childhood as a condition of experience, which can be potentialized by writings and readings that might enable other ways of thinking and existing. Keywords: time; childhood; reading and writing practices.

\section{LIRE ET ÉCRIRE COMME POSSIBILITÉ D'UNE RELATION ENTRE L'ENFANT ET LE TEMPS}

\section{RÉSUMÉ}

Cet article explique comment les enfants ont été mis en relation avec le temps, à travers l'examen des livres scolaires rassemblés dans l'État de Rio Grande do Sul de 1923 à 2016, et à partir de l'examen des ateliers organisés avec des étudiants et des enseignants d'écoles publiques. On souligne, sur le plan archéologique, le déplacement des pratiques d'écriture et de lecture qui thématisaient la vie et la mort vers un décompte chronologique du temps, dans lequel l'enfance est racontée comme une promesse d'avenir et, plus récemment, traversée par les symptômes de l'accélération, performance et instrumentalité utilitaire. On choisit donc de considérer l'enfance comme une condition de l'expérience, potentialisée par des écritures et des lectures qui pourraient rendre possibles d'autres modes de pensée et d'existence.

Mots-clés: temps, enfance, pratiques d'écriture et de lecture. 


\section{EM TEMPOS VORAZES: UMA ESCRITA}

Pois qual o valor de todo o nosso patrimônio cultural, se a experiência não mais o vincula a nós. (BENJAMIN, 2012, p. 124).

Em tempos de entretenimento voraz, de super aceleração e desempenho em que se compete consigo mesmo, em tempos em que todos dizem não ter tempo, toma-me o desejo de estudar a escrita e a leitura na escola. Com alguns roubos arquegenealógicos, busco descrever certos sintomas de nosso presente a partir da problematização do que temos por mais habitual: nossas relações com o tempo.

Esta escrita é composta de um recorte de uma investigação que se valeu de pesquisa bibliográfica, de experimentações por meio de oficinas com professores e alunos do Ens. Fundamental de escolas públicas gaúchas e, especialmente, do exame de cadernos escolares dos anos iniciais do Ens. Fundamental de diferentes localidades do estado do Rio Grande do Sul (datando de 1923 a 2016)². Os cadernos aqui são tomados como importantes dispositivos escolares de atenção, que guardam uma memória e que também atravessam os modos de subjetivação.

Vivemos em tempos em que são confundidas: aulas com plataformas de vídeo; professores com facilitadores e mediadores; alunos com clientes em sala de aula e empresários de si; estudo com conectar e armazenar informações

\footnotetext{
${ }^{2}$ O HISALES é um grupo de pesquisa vinculado ao PPG em Educação da UFPel que reúne pesquisadores de várias instituições de ensino da região sul, contando com a participação de pesquisadores e de alunos. O HISALES tem procurado estabelecer uma política de recolha, tratamento e guarda de objetos da cultura escolar, constituindo, assim, importante acervo para a pesquisa educacional. Ver mais em: http://www.ufpel.edu.br/fae/hisales/. Nosso Grupo de Pesquisa, vindo de outra Universidade, visitou o acervo e pode realizar o processo de organização e digitalização de cadernos dos anos iniciais do Ens. Fundamental. Do mesmo modo, foram examinados cadernos de uma Rede Municipal de Ensino da região metropolitana de Porto Alegre /RS, recolhidos e digitalizados no ano de 2016, mediante visitas em duas escolas com turmas do $4^{\circ}$ ano do Ens. Fundamental. Nestas mesmas escolas, conseguimos doações de cadernos particulares, datados de 2005 à 2008, de $3^{\circ}$ e $4^{\circ}$ ano do Ens. Fundamental. Ainda, foram recolhidas produções escritas de alunos de $5^{\circ}$ ano do Ens. Fundamental em uma escola da serra gaúcha, também no ano de 2016. Totalizamos 75 cadernos escolares nestes três movimentos de recolhimento, datados de 1923 a 2016.
} 
velozmente, em que não se pode mais falar em ensino, porque o importante seria o aprender a aprender. A partir disso, uma questão chama atenção nos materiais examinados: a escrita vinculada a certa relação com o tempo, podendo evidenciar que, historicamente no Brasil, a escrita sempre esteve atravessada por certa velocidade, vinculando rapidez, utilidade e boa escrita (SCHULER, 2017). É interessante notar que, enquanto no início do século $X X$, as crianças registravam dois ou três exercícios por dia em seus cadernos, no começo do século XXI, isso se amplia para mais de 10 exercícios em um turno. De que tipo de atenção estamos falando? De que tipo de pensamento, escrita, leitura e estudo estamos falando? E, juntamente com isso, como essas crianças estão valorando suas relações com o tempo, no tempo, por meio do tempo?

A partir dessa brevíssima descrição, interessa-me pensar como tomar essa questão perguntando com algumas boas companhias. Poderíamos perguntar com Foucault (2002a, 2011) e Nietzsche (2009): entre uma infinidade de enunciados, por que aparecem esses, e não outros em seu lugar? O que estamos fazendo de nós mesmos e dos outros nesses tempos de formação escolar, nessas escritas escolares? Que léxico estamos usando com as crianças na escola quando tomamos o mundo e, especificamente, o tempo? Como ler e escrever sem intervalos na escola? Como ler e escrever, de modo problematizador, nossas relações contemporâneas com o tempo? Como problematizar o nosso contemporâneo? Perguntar de outras maneiras não seria um modo de conspiração, de maquinação de outras coisas além do tédio paralisante ou da inovação pela inovação?

Alguns, talvez, argumentem que a leitura e a escrita na escola sejam armas fracas demais em se tratando dos tempos em que vivemos, mas, ainda assim, são armas. Ou melhor, poderiam ser pensadas como equipagens no sentido estoico para certo combate a ser arquitetado, bem como um modo de companhia e de defesa. Defesa, como diria Didi-Huberman (2011, p. 38), de uma "[...] ditadura industrial e consumista em que cada um acaba se exibindo como se fosse uma mercadoria em sua vitrine, uma forma justamente de não 
aparecer".

Por isso este artigo coloca-se como um manifesto que quer pensar certa relação com o tempo e a infância. Se a escola é o local de transmissão e problematização da cultura por excelência, como estamos produzindo e registrando as pequenas vidas que por ali passam, suas questões cotidianas, seus pensamentos menores, suas inquietações, suas perguntas, suas buscas? Lembro-me do documentário de Marcelo Masagão: "Nós que aqui estamos, por vós esperamos”. Caso fôssemos contar a história do século XX por meio desses cadernos examinados, quais memórias apareceriam? Apareceriam, pela regularidade que esta pesquisa conseguiu examinar: servidão à pátria, ao trabalho, à Deus, à família, ao tempo esquadrinhado, à infância romantizada. Que imagens do século XX produzimos com essas crianças ao longo desses anos? Cada vez que uma criança nasce, cada vez que uma criança ingressa em uma escola, surge a possibilidade de lhe contarmos deste mundo. Assim, quais relações com o tempo estão sendo vividas? Como isso produz condição de possibilidade para os discursos neoconservadores que se alastram no contemporâneo e que falam em nome de Deus, da pátria, da família e da defesa da infância?

Assim, este artigo traz inicialmente uma discussão sobre a leitura, a escrita e a escola moderna, com seus atravessamentos disciplinares, bem como a escola no presente sendo implicada pelos enunciados do desempenho, das competências, do excesso de estímulos e de informações. A partir disso, busco possibilidades de tomar a escrita e a leitura por sua potência ética, recorrendo ao conceito de cuidado de si em Foucault (2011), o que irá implicar em uma outra relação com a atenção e com o tempo. Na sequência do texto, a partir de tais ferramentais analíticos, da realização das oficinas em escolas públicas e do recolhimento de 75 cadernos escolares, são examinados 48 exercícios de escrita a partir de 19 cadernos selecionados para esse artigo, datando entre 1923 e 2016, saltando-me aos olhos uma questão menor: a infância e o tempo.

No início do século XX, uma menina registra no final do seu caderno a 
lista dos mortos da sua comunidade. Infância, tempo, vida e morte atravessando a escrita dessas crianças. Essa lista é acompanhada por textos que discutem a angústia e a tristeza. Esse tipo de escrita, que relaciona o tempo, a vida e a morte, desaparece dos cadernos examinados, dando espaço à contagem do tempo em segundos, minutos e horas; à organização do calendário em dias, semanas, meses e anos. Mais recentemente, evidencia-se uma preocupação exacerbada das crianças com a produtividade do tempo e sua passagem cada vez mais rápida, narrando a velhice como inútil, pois não fazem mais "nada". Em um século em que ainda se luta contra o trabalho infantil no Brasil, talvez nunca as crianças se preocuparam tanto em se tornarem produtivas, e isso significando trabalhar, consumir e acumular, de certa forma.

Encerro esse texto perguntando pela possibilidade de uma relação mais infantil com o tempo, tomando aqui a infância como uma condição da existência (AGAMBEN, 2005). Isso significar perguntar pela possibilidade, quando se trata da leitura e da escrita na escola, de uma relação de maior contemplação, ruminação, conversação, escuta e experimentação com o mundo, com o outro e consigo mesmo. Uma relação que passa, ainda, por esse espantar-se com o mundo, de ter tempo para se ter intimidade com o que se pensa e que problematiza esse tempo da fabricação que narra as crianças como promessa de futuro em termos de desempenho e produção.

Tenho a clareza de que os cadernos escolares não dão conta de dizer de um todo que acontece na escola em um século e em um estado, pois lidamos com fragmentos. E a lógica totalitária e exaustiva nem mesmo é o que se pretende neste tipo de pesquisa. Porém, por ser o caderno, ainda hoje, o principal dispositivo de escrita e leitura na escola, temos condições de tomá-lo para pensar nos lugares de infância que implicam. Mais recentemente, muitas são as pesquisas no campo da educação que vem se utilizando de cadernos escolares como fonte documental, uma vez que se constituem, ainda no presente, como central nos processos de ensino e de aprendizagem (GRAZZIOTIN, 2015). Soma-se isso o argumento do historiador português 
Jorge Ramos do Ó, quando argumenta que os cadernos escolares estão fortemente vinculados a essa lógica documental moderna, nos quais são feitas as inscrições individuais dos alunos, em que seus modos de subjetivação vão sendo produzidos e presos a essa lógica documental (Ó, 2003).

Desse modo, busco problematizar a relação entre infância e tempo, tomando como inspiração a perspectiva arquegenealógica a partir dos estudos de Nietzsche (2009) e de Foucault (2002a, 2002b, 2011). Portanto, entendo a história não como uma pesquisa de origem que busca a evolução, o sentido original, mas justamente busco diagnosticar os sintomas do nosso tempo, compreendendo que a verdade tem uma história e é o principal efeito das relações de poder. Por isso se fez importante mostrar esses corpos marcados de história, como superfície de inscrição dos acontecimentos (FOUCAULT, 2003), evidenciando as descontinuidades que os atravessam, quando vinculam certos sentidos e modos de experimentar a condução das condutas. Assim, Veiga-Neto (2000, p. 16) nos ajuda a pensar essas relações entre a escola, o tempo e subjetivação, dizendo que "a percepção do tempo não é um a priori, como pensou Kant. Ao contrário, ela resulta de uma construção social; a percepção do tempo -como a do espaço-é, portanto, contingente”.

Trata-se, pois, de um artigo que pretende falar uma língua um pouco mais herege, à maneira de Nietzsche (2009), e escrevendo em um tempo menos morto, menos achatado, mais aberto ao abismo, tentando desdomesticar o mais doméstico em nós. Um manifesto por um tempo-cuidado que preza pela utilidade do inútil e que necessita de outra narração; uma infância do tempo.

\section{ESCRITA, LEITURA E TEMPO: POR UMA VIDA}

Por que escrevemos na escola? O que escrevemos? Cada um fala de si. Mas aqui não se trata de um $e u$ inchado. Trata-se de um si, de uma relação, de modos de subjetivação. Por isso, não se trata aqui do sujeito que escreve, mas de 
certa relação com a escrita. Se operamos com a lógica de quebrar com a perspectiva de uma ideia no geral para trabalhar com as infinidades dos modos de expressão, podemos nos perguntar sobre essa expressão utilitária, do registro, que não suporta o insuportável da vida (DELEUZE, GUATTARI, 2002), que circula majoritariamente na escola. $E$, se fazemos isso, não é para "bater" na escola. Pelo contrário. É por sua importância como elemento vital de nossa cultura que tentamos, penso eu, colocar questões que potencializem a grandeza pedagógica. Quais são as questões que temos produzido em educação quando nos perguntamos sobre a escrita e as infâncias? Como fazer afastamentos provisórios do maior, do binário, da normalização, para tomar a discussão entre escola, infância, tempo e cuidado?

A lógica disciplinar obriga-nos, a todo momento, a colocarmo-nos em discurso. Em sua grande maioria, o faz em matrizes cognitivistas, por meio de codificadores confessionais, buscando autodecifração, classificação ou reconhecimento. No deslocamento para uma sociedade de controle (DELEUZE, 2008), ou para uma sociedade do desempenho (HAN, 2015), continuamos sendo interpelados pela necessidade de colocarmo-nos, agora no presente, em discurso de tipo narcisista, de exposição espetacular e de produção super acelerada, em uma competição com nós mesmos, em que o cuidado se dispersa para a sobrevivência contemporânea. Vivemos o imperativo e a pressão por desempenho e produção. Para Han (2015, p. 31), nesse excesso de estímulo e informações, modifica-se "[...] radicalmente a estrutura e economia da atenção. Com isso se fragmenta e destrói a atenção". Por exemplo, a técnica temporal do multitasking impede-nos um olhar mais contemplativo e problematizador conosco, impede-nos de escutar o outro, de pensar a vida. Paradoxalmente, talvez a escola ainda seja um dos poucos lugares para a contemplação, para fazer o "inútil", como ler um poema, escrever um conto, copiar do quadro um texto à mão. Mas e quando fazemos 10 exercícios de cópia em um turno, o que nos sobra para o exercício do pensamento? Como podemos pensar aí o cuidado conosco em uma perspectiva foucaultiana (FOUCAULT, 2011)? 
Desse modo, o que pretendo é tomar o cuidado de si vinculado a certa atenção, como discutido por Foucault (2011). Hadot (2016) lembra-nos de que os princípios operados na antiguidade clássica seriam muito importantes à nossa atual democracia, o que nos exigiria alguma atenção - a atenção que tem a ver com o estudo, com certo tipo de escuta com o texto, com a vida e consigo. $\mathrm{Na}$ etimologia da palavra atenção, está atender, que está vinculado a esperar e aguardar, a estar atento, vigilante (CUNHA, 2010). Já quando tomamos o conceito de vigilância, logo nos remetemos à disciplina e à coerção sem folga sobre as operações do corpo, como falava Foucault (2002b). Todavia, podemos tomar a vigilância como uma condição para essa relação do tempo do cuidado que exige certa atenção, o que poderá operar outra micropolítica em se tratando da leitura e da escrita na escola.

Se tomamos a vigilância na perspectiva estoica de Sêneca (2011a), podemos pensar que ela não remete à confissão de uma parte estragada de nós, como na lógica cristã, mas a um tipo de exame que volta o olhar para os modos como estamos vivendo nossas vidas. Uma vigilância que nos mantém alerta aos males de um tipo de agitação cotidiana que faz com que abandonemos o mais importante. Uma vigilância que diz respeito a exercer certa guarda e equipagem de si para fugir ao máximo da escravidão. Essa vigilância poderia ser lida como um tipo de cuidado, um tipo de atenção que pede recolhimento via leitura (o que poderia ser lido como uma arte) para que possamos transformar o que recolhemos. Tratar-se-ia, portanto, de um delicado processo de extração e disposição, objetivando transformar o que recolhemos em outra coisa, em força, o que exigiria um árduo trabalho - exigiria ruminação, outra relação com a infância e o tempo.

Isso nos leva à discussão que Foucault (2011) realiza sobre o cuidado de si na antiguidade greco-romana, quando tomo o segundo momento por ele analisado, qual seja, o dos primeiros dois séculos de nossa era. A primeira característica é que o cuidado de si deverá acompanhar toda a nossa vida, sendo como uma fórmula da arte de viver, uma preparação para a velhice. A segunda 
característica é que pode ser aplicado por todos. Embora a prática de si seja dirigida a todos, poucos conseguem operá-la, pois cuidado exigiria o "ócio cultivado", o que traz uma separação social e econômica. Por isso, tratava-se de uma forma rara de existência. A terceira característica destacada é que essa prática é atravessada pelo outro, seja pela mestria do exemplo (do mestre, dos poetas utilizados), pela mestria da competência (transmissão dos conhecimentos aos mais jovens) ou pela mestria socrática (do diálogo e do embaraço). Então, por que tomá-la para pensar práticas contemporâneas em uma instituição de massa como a escola? Porque Foucault cita essas figuras de mestre para justamente problematizar um mestre da memória que supre o outro de uma suposta ignorância, para potencializar a figura de um mestre que convida o outro a cuidar de si mesmo de maneiras diferentes (FOUCAULT, 2011).

Para isso, a agitação do pensamento torna-se nefasta. A agitação, a stultitia é o outro da prática de si, porque é precisamente aquele funcionamento que aceita tudo o que vem sem o devido exame, sem a devida atenção. "O stultus é alguém que de nada se lembra, que deixa a vida correr, que não tenta reconduzi-la a uma unidade para rememorização do que merece ser memorizado, e que não [dirige] sua atenção, seu querer, em direção a uma meta precisa e bem determinada. [...] Sua vida, sua existência passa, portanto, sem memória nem vontade" (FOUCAULT, 2011, p. 119). Portanto, o cuidado de si teria como um dos princípios fundamentais o tempo livre como que implicado na relação com a liberdade, ou seja, a luta contra uma ocupação servil de todo o tempo.

Daí a importância desses conceitos para tomarmos a escola contemporânea, não como vontade nostálgica de aplicação de outra época, mas como ferramental analítico para pensarmos o nosso presente. Foucault parte principalmente da discussão dos estoicos para falar da diferença de educare (vinculado à transmissão e às habilidades) e educere como esse puxar, conduzir para fora de si. E não seriam os processos escolares a conexão desses dois 
movimentos? E como tomar a escrita e a leitura como operadoras desses processos? Foucault (2011) remonta ao sentido de skholé na forma helênica, com caráter fechado e existência comunitária dos indivíduos, guiados por um mestre, segundo os epicuristas, por exemplo. Já nos exercícios estoicos, observam-se práticas de reuniões muito exigentes, com várias categorias de alunos. Em outras formas romanas, encontramos os conselheiros privados da existência. E nessas perspectivas da antiguidade, a aceleração era o outro da vida e do pensamento.

Remeter o contemporâneo à ideia da escola como tempo livre, valorando o cultivo do ócio, talvez possa funcionar como uma forma de identificarmos os inimigos de uma leitura e de uma escrita do tempo do cuidado com certa atenção na escola. Isso não significa abandono intelectual, pelo contrário, uma vez que o exercício do pensamento pede pelo intervalo e, talvez, um dos poucos lugares que, mesmo atravessada pela aceleração, ainda seja possível de alguma suspensão seja justamente a escola.

Todavia, a escola moderna nasce como uma instituição de confinamento (FOUCAULT, 2002b), com fins civilizatórios e moralizantes, articulando forças disciplinares e biopolíticas, transformando crianças em alunos, atravessando-os como indivíduos e como população em uma sociedade capitalista que se produzia no início da Modernidade. Assim, fez-se necessário ensinar as crianças a ler e a escrever no idioma de seus países como uma forma de construção das identidades nacionais, marcados pelo tempo esquadrinhado.

$\mathrm{Na}$ sociedade disciplinar, ler e escrever eram entendidos como habilidades para formar o bom cidadão, a partir do trabalho civilizador (SIBILIA, 2016). Portanto, a discussão das habilidades da escrita e da leitura não estava desvinculada da moralização (o que fica fortemente evidenciado na constituição da história da literatura infantil). Tem-se aí toda uma discussão da substituição do trabalho infantil pela educação, discurso esse que, nos cadernos examinados, aparecerá somente na segunda metade do século XX. Até então, as crianças narravam-se trabalhando nas lavouras das famílias, e somente na 
segunda metade do século XX começa a aparecer o discurso das crianças necessitando estudar como uma preparação para o mercado de trabalho no futuro3.

A partir daí começa a evidenciar-se nos cadernos examinados, cada vez mais, a força do discurso de futuro. Por isso é tão difícil estar presente, viver o instante, pois "nossa escola é filha do mundo moderno, e a Modernidade foi um grande projeto, uma maneira de entender e dar sentido ao mundo através do futuro. Suas palavras de ordem são: progresso, evolução, revolução, ruptura, desenvolvimento, mudança”. (LÓPEZ, 2015, p. 143). Leite (2011) discute essa relação ainda muito cristã com o tempo, marcada por uma ideia de início e fim, tornando-o linear. A Modernidade retoma e fortalece essa lógica pelo viés do progresso. As ciências humanas, em especial os discursos pedagógicos, vão operar nessa lógica a partir da ideia de desenvolvimento infantil. Mais contemporaneamente, a essa perspectiva, somam-se os enunciados do produtivismo e da aceleração.

No presente, experimentamos outras forças que não só do disciplinamento, mas a constituição do que se denominou sociedade de controle, marcada pelo controle do controle, pelas tecnologias eletrônicas e digitais, por um consumo exacerbado e uma lógica de superprodução, pela força do marketing e das redes de comunicação (DELEUZE, 2008; SIBILIA, 2016). Não temos mais a fábrica como modo de funcionamento, mas a empresa e todo o seu léxico invadindo as escolas. Por isso, faz muito sentido falar que vivemos em uma sociedade do desempenho, da autossuperação, em que se passa a concorrer consigo mesmo em diferentes níveis de autogerenciamento (SIBILIA, 2016; HAN, 2017).

Dessa forma, práticas de leitura e escrita marcadas pela disciplina, pela repetição, pela cópia, pelo silêncio, pela obediência, pela dedicação concentrada, com metas de longo prazo, com esforço recompensado, em um tempo

3 Ver Dullius (2019), que discute a emergência do aluno trabalhador no Brasil, descrevendo o quanto crianças bem pequenas eram inseridas em escolas de ofícios, não havendo uma separação clara entre preparação para o trabalho e infância ainda no início do século XX. 
quadriculado e esquadrinhado, vão se deslocando quando os modos de subjetivação contemporâneos são atravessados pelo rápido prazer, pela livre iniciativa, pelo interesse de cada um, pela satisfação imediata (SIBILIA, 2016). E aqui não se trata de uma nostalgia pedindo a volta da disciplina fabril, mas de pensar como essas práticas no presente estão também jogando o jogo das subjetivações marcadas por essa dispersão, pelo acesso rápido à informação, pela fragmentação, pelo individualismo exacerbado e pela falação opiniática.

Vivemos uma época em que a educação se reduz a habilidades e competências, ao útil, ao que pode ser medido, classificado, tornado mercadoria. A escrita e a leitura estariam, assim, focalizadas "[...] na instrumentalidade utilitária mais pontual do tipo empresarial”. (SIBILIA, 2016, p. 70). Isso porque ler e escrever na escola estariam associados a desenvolver "[...] competências necessárias para realizar um conjunto limitado, embora bastante útil, de operações práticas”. (Ibidem., p. 72). Essa questão aparece muito fortemente nas falas de alunos dos anos iniciais do Ens. Fundamental de uma escola pública da região metropolitana de Porto Alegre, onde desenvolvemos oficinas com alunos e professores em 2018. Quando a linguagem instrumental aparece com tamanha força e com regularidade nas políticas públicas contemporâneas, nas falas de alunos e professores, nas produções acadêmicas, podemos entender como esse léxico instrumental é assumido como uma linguagem universal para falar da educação e de si mesmo. Linguagem essa implicada fortemente nos processos de aceleração e produção exacerbada. Assim,

O que nos propomos não é uma defesa da escrita, mas a garantia a certa política. Mesmo que aparentemente sossegadas, as formas carregam consigo limiares, quanta político - resta que estejamos atentos a isto e que possamos arquitetar nossos próprios dispositivos de acolhimento e de recusa. Uma política da escrita se faz sob a lâmina fina de uma atenção capaz de nos ajudar a pensar as escritas que nos assediam, os textos que lemos e escrevemos, os usos e subserviências da linguagem escrita em nosso presente. (COSTA, 2017, p. 14). 
É interessante pensar que esses mesmos alunos narram que pulam de um exercício a outro e mal conseguem descrever como leem e escrevem na escola. Apresentam uma atenção rápida, dispersa, exigindo novas motivações a cada minuto, exigindo do texto escrito a mesma resposta rápida que encontram em outros suportes, tais como os vídeos do YouTube, principal fonte de estudo. Estariam as práticas de leitura e escrita, os investimentos em livros de literatura e produção de textos, tornando-se anacrônicos no presente? Poderiam, ainda, ser pensadas como práticas de subjetivação que marcam e inscrevem sulcos na vida dessas crianças? Qual o lugar do pensamento, da problematização de si e do mundo quando os valores estão focados na opinião, na informação atualizada e na valorização do interesse pessoal? Seria ainda possível falarmos de alunos leitores, alunos escritores? Tédio, hiperatividade, excesso de estimulação e incapacidade para lidar com o sofrimento e a frustração seriam marcas das infâncias contemporâneas? E como isso impactaria no modo como estão vivendo suas relações com o tempo?

Diz Sibilia (2016, p. 91-92) que "a saturação total impede de pensar e agir. Por isso é tão vital resistir ao fluxo mediante estratégias de fixação, algo que a escola contemporânea deveria assumir como um dificílimo compromisso". Isso fica fortemente evidenciado na fala de uma das professoras participantes de uma das oficinas quando diz que seu sofrimento reside na aceleração, em que nada dura e se fixa o suficiente para poder respirar o que se passa (SEIBERT, 2018). Não se trata de advogar por uma fixação identitária, mas de fazer algo durar o suficiente para se ter intimidade com o pensamento. Daí que o ferramental foucaultiano do cuidado de si me interessa, justamente para problematizar algo para o qual os gregos já chamavam atenção: o perigo da stultitia, essa agitação, essa impaciência com a vida que o nosso contemporâneo parece viver com tanta ferocidade que não permite que se produza pensamento, sentido, exercícios de si (FOUCAULT, 2011).

Quando o valor da velocidade triunfa sobre o valor da consistência, podemos pensar melhor sobre o que estamos fazendo de nós mesmos. Por isso, 
interessa-me pensar como as crianças estão narrando e registrando, nos cadernos examinados, suas relações com o tempo. Isso porque "[...] toda cultura é, primeiramente, uma certa experiência do tempo, e uma nova cultura não é possível sem uma transformação desta experiência”. (LEITE, 2011, p. 107). Portanto, "tudo passa, essa é a convicção suprema sobre a qual se ergueu o mundo moderno. O passar é a essência do tempo. Mas o passar do tempo é sempre inapreensível. Mas foi a captura mercantil da mudança e sua aceleração que acabará tornando o tempo moderno definitivamente inabitável”. (Ibidem, p. 107).

A partir disso, poderíamos problematizar essa lógica de linearidade operada via discursos de futuro, desenvolvimento e evolução que marcam os processos formativos das crianças e pensar as práticas de leitura e escrita para tomar o tempo como acontecimento, como emergência de outras forças. Em uma sociedade do espetáculo, onde o audiovisual exerce tamanha força, qual o tempo para o exercício com a palavra escrita? Qual o sentido dos clássicos exercícios de leitura e escrita na escola? Qual seria no presente, então, o espaço na escola para a experiência, para certo exercício de pensamento e vida com a escrita e a leitura nesses ritmos, neste tempo cronos contemporâneo?

\section{INFÂNCIA, TEMPO E ESCRITA ESCOLAR: DOS MORTOS À VIDA PRODUTIVA}

Poderia a escola operar na lidação com as práticas de escrita e leitura atenta à lidação com o tempo, no sentido de justamente encontrar furos no texto, não para denunciar a falta de consistência, mas para respirar entre eles? A partir disso, trago alguns excertos dos cadernos examinados para fazer um rabisco na areia, marcando uma história, mas fazendo-o no papel, porque há algum desejo maior de duração. Assim, estabeleci alguns deslocamentos em se tratando das relações narradas pelas crianças nos cadernos com o tempo. 


\section{Infância, tempo, vida e morte}

Figura 1: As três lágrimas

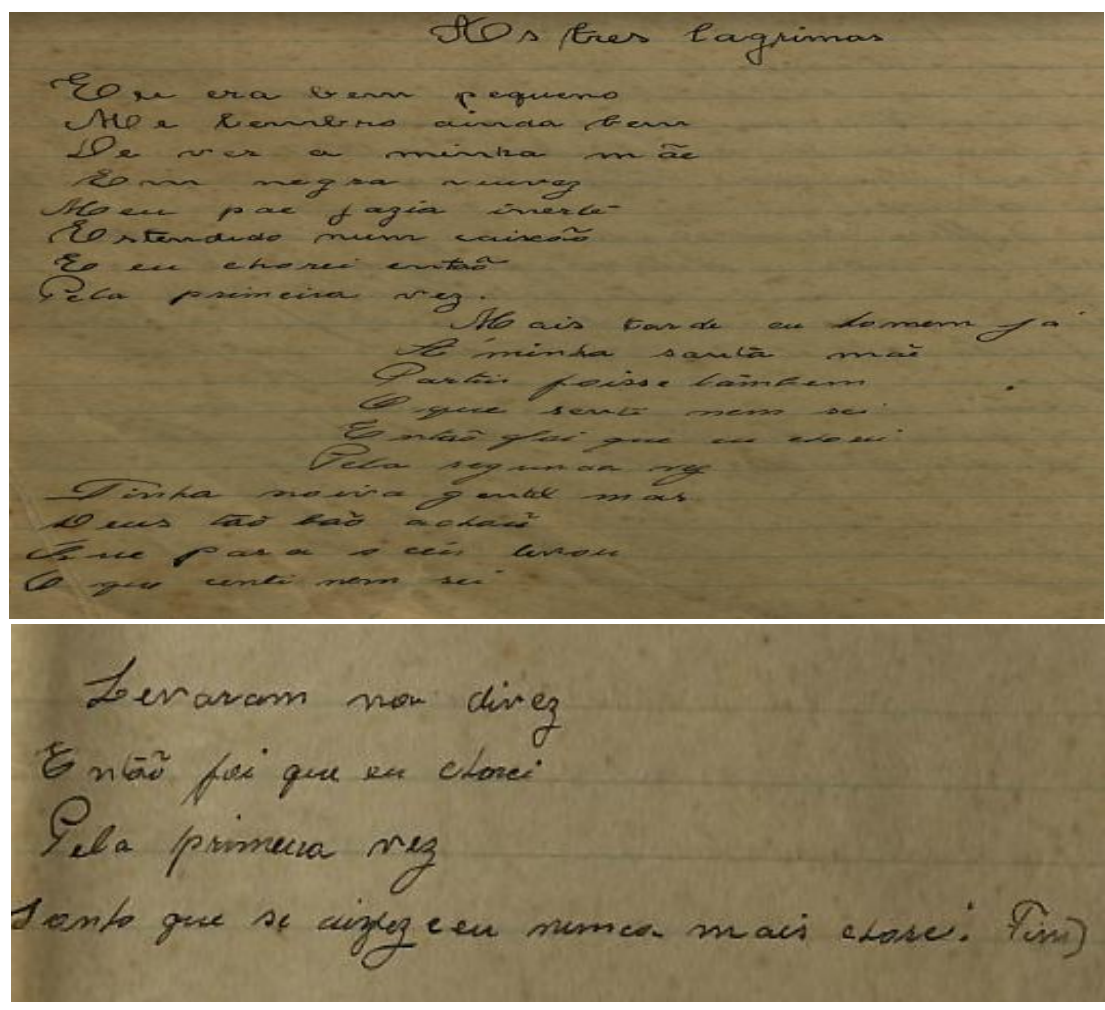

Fonte: Hisales (Caderno de 1923)

Em um caderno escrito por uma aluna da segunda série em 1923 na região sul do estado, encontra-se, no final do documento, uma listagem dos mortos da comunidade, destacando-se a data da morte e a idade das pessoas 4. Essa listagem vem acompanhada por textos sobre a angústia, tematizando a morte e o sofrimento. Escrevia-se sobre os mortos, sobre a morte, sobre a angústia e a tristeza. Não apenas os grande heróis (também eles), mas nossos vizinhos, parentes, conhecidos que habitavam nossa comunidade. Eles estavam nos cadernos escolares. Havia certa memória da vida e da morte. Hoje não mais habitam esse espaço. Não há tempo para eles. Nem mesmo como fantasmas ou espectros. Hoje há tempo somente para falar da vida sadia, de sua prolongação,

\footnotetext{
${ }^{4}$ Essa parte do caderno não foi inserida em respeito aos nomes citados.
} 
de sua produtividade e do controle dos riscos.

Sêneca (2011b), discutindo a morte, apontava a necessidade da preservação da lembrança. E mais: dizia que o sofrimento com a morte não vem com algo que já sabemos, mas com o desperdício do tempo (que é a única coisa que deveria despertar avareza). Por isso, uma vida não é curta ou longa a partir da contagem dos anos, mas a partir do que se fez com ela. Se não concretizarmos nada, se não respeitarmos nenhum valor, se não realizarmos nada, não importa quanto tempo vivermos, nossa vida será curta. Por isso, a duração não se conta em tempo cronos, mas fala de certa estética da existência, como diria Foucault (2011). O que me leva a pensar em um outro tipo de atenção em Kafka: a sabedoria sobre a brevidade da vida, um tema estoico tão antigo.

Não sabemos como esses textos dos cadernos foram trabalhados. O que podemos descrever são quais textos e tipos de exercícios estão ali registrados. Isso nos fala de alguns sintomas. O que chama muito a atenção é que essa listagem dos mortos da comunidade ou textos que tematizam a morte e o sofrimento desapareceram dos demais cadernos examinados.

Pagni (2010) argumenta a favor de uma prática pedagógica que receba os recém-chegados ao mundo por meio de um pensamento engajado para entender tal mundo e de uma sabedoria para conduzir sua própria vida, como que um cultivo de si, muito diferente da lógica das habilidades e competências, tão aclamadas no presente. A partir disso, o autor argumenta que, assim como o nascimento, a morte é “[...] outro acontecimento do qual apenas nos cercamos nessa experiência de tempo finito e, de modo mais incisivo, para deparar-nos mais ainda com nossa própria finitude" (Ibidem, p. 67). Ele continua, argumentando que isso "[...] nos faz olhar de modo distinto para as nossas vidas, ou melhor, o que dela nos resta.” (Ibidem, p. 67). Podemos pensar, a partir disso, o quanto tematizar a morte e a tristeza na escola pode abrir para olharmos para outros modos de existir que têm a potência de intensificar a vida, esse tempo que nos resta, talvez podendo funcionar como um mecanismo do 
cuidado de si. Além disso, poderia ter a potência de tornar-nos mais sensíveis ao sofrimento do outro. Ou seja, pode ser uma brecha para vivermos o que nos acontece e o que acontece aos demais que nos cercam, com a novidade que se lhe apresenta e com a decência que se merece.

Desse modo, poderíamos pensar as práticas de leitura e escrita como constituição do tempo. Poderíamos pensar a escola atravessada por essa potência de operar um tempo, outro tempo, com narrativas que vão criando outros sentidos, alargando o que pode ser pensado e vivido, mas o que vemos nos cadernos escolares neste último século é justamente um deslocamento do importante para o útil. Por exemplo, a discussão sobre a morte (as poucas vezes em que aparece) não está mais associada à finitude, à homenagem e à memória, à tristeza e à vida, mas conectada ao enunciado do risco. Ou seja, nessa biopolítica contemporânea, vemos toda uma discussão nos cadernos em que as crianças passam a se narrar mais recentemente como um risco em potencial para o meio ambiente se não tiverem os comportamentos adequados. O risco substituiu a angústia e a tristeza. O risco pode ser calculado, previsto, gerenciado. A vida entendida em sua perspectiva trágica, não.

Podemos seguir com Ordine (2016, p. 24), para quem "[...] o bom é sempre melhor que o útil". Porém, em nossos tempos, o útil vem colado à ideia de progresso e de melhoria do humano. Se estamos em deslocamento de uma sociedade disciplinar para uma sociedade do desempenho, talvez nosso modo contemporâneo de governo passe fortemente pelo "útil" e pelo abandono da memória. Não há tempo para a tristeza, porque esta seria o outro do sucesso. Sêneca já nos lembrava que úteis são os saberes que transformam a nossa experiência. Assim,

Especialmente nos momentos de crise econômica, quando as tentações do utilitarismo e do egoísmo mais sinistro parecem ser a única estrela e a única tábua de salvação, é preciso compreender que exatamente aquelas atividades que não servem para nada podem nos ajudar a escapar da prisão, a salvar-nos da asfixia, a transformar uma vida superficial, uma não vida, numa vida fluida e dinâmica, numa 
vida orientada pelo curiositas em relação ao espírito e às coisas humanas. (ORDINE, 2016, p. 19, grifo do autor).

Coisas humanas: a vida e a morte. Interessante pensar que, em algumas experimentações com oficinas filosóficas realizadas com crianças em cidades diferentes do estado do Rio Grande do Sul entre 2016 e 2018, quando se trazia os temas do tempo, a infância e a vida, as crianças escreviam e falavam sobre a morte (LERMEN, SCHULER, 2018; SEIBERT, 2019). Faziam-no a partir de uma perspectiva que não a separa da vida, que não aparta o sofrimento da vida, que valoriza o instante e que se coloca a pensar sobre e com o tempo.

Figura 2: Antes do tempo

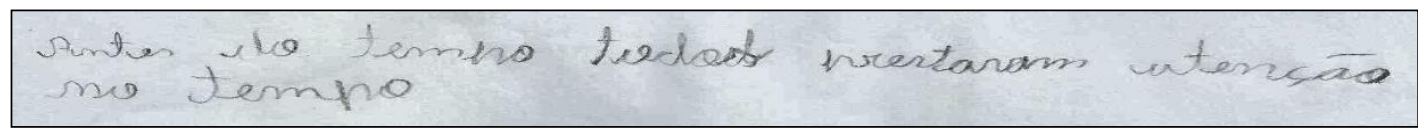

Fonte: Caderno recolhido em escola Municipal de Ensino Fundamental na serra gaúcha em 2016.

Um tempo antes do tempo. Um tempo antes da contagem cronológica do tempo. Isso é tornado pensável por meio da produção escrita. Um tipo de experiência tornada linguagem escrita sem o desejo de tornar-se discurso de verdade. Talvez uma escrita que não deseja ser ponto de destino, mas uma viagem que torna possível o pensamento.

Em outra oficina filosófica com crianças na região metropolitana de Porto Alegre em 2018 crianças, operando uma relação com a infância do pensamento, produziram imagens de vida e de morte quando falam, por exemplo, de um funeral e da boniteza de uma fila de amigos que poderia atravessar cidades (SEIBERT, 2019). Isso porque o nascimento e a morte partilham o murmúrio, a não palavra. Por isso a boniteza de pensarmos em uma infância do pensamento em uma linguagem não gregária, em uma infância do tempo, podendo operar com as práticas de escrita e leitura que tenham como princípio primeiro o processo de formação, de abertura à potência e à criação. 
Isso exige manter a relação com o abismo o mais próximo possível, assim como outra relação com o instante para que possa haver pensamento.

Se o instante não é o outro de nossas vidas, não é o que mantém a continuidade de presente e passado, este passa a ser valorado de outras formas. Essa lidação infantil com o tempo, a vida e a morte, essa lidação trágica com a existência, poderia ensinar-nos outros modos de ler e escrever na escola. Poderia ser esse um manifesto. Isso porque "é fazendo a experiência de ter que dizer o que não se sabe dizer e de pensar o que não se sabe pensar que o ser humano se torna tal. É fazendo a experiência de esse não ter palavras para dizer o que se necessita dizer, que se pode falar humanamente” (LÓPEZ, 2015, p. 153).

Essa talvez seja uma grandeza pedagógica da escola: práticas de escrita e leitura que justamente abrem outra relação com o tempo, que se perguntam pela ampliação na quantidade de exercícios feitos em um turno, que se perguntam que tipo de relação com o tempo está sendo operado quando lemos e escrevemos dessa forma e sobre essas coisas e não outras. Outra grandeza talvez seja fraturar essas linhas que buscam o pragmatismo a qualquer preço em uma lógica comercial, lendo, escrevendo, conversando e produzindo interrupções para tornar possível alguma ruminação, algum abandono de si, alguma outra experiência com a vida e o pensamento. Pensar a escrita e a leitura útil justamente como aquelas que nos tornam mais dignos (ORDINE, 2016).

\section{INFÂNCIA E O TEMPO NO FUTURO: OS CINCO RELÓGIOS E AS PEQUENAS VIDAS UTILITÁRIAS}

Em um caderno de 1937, aparece um texto intitulado "Cinco Relógios", descrevendo os ponteiros do relógio e as horas. Em outro caderno, de 1938, destaca-se a cópia de um texto intitulado "O levantar", narrando a rotina de um dia, incluindo aí as tarefas de rezar, almoçar com a família e ir para a escola, 
iniciando com a mãe acordando o filho às $6 \mathrm{~h}$. Outra cópia de texto desse mesmo caderno, intitulado "Da manhã em nossa casa", descreve o pai acordando o filho às 5 h e a mãe chamando-o de "o grande dorminhoco", narrando a rotina da leitura de livros escolares, ida à escola, atividades na fazenda (como tirar leite de vaca) e o almoço em família. Em outro caderno, que inicia em 1938 e é concluído em 1939, pontua-se um texto com o título "O anno", no qual é descrito um calendário de 365 dias, 12 meses e 52 semanas, as quais se organizam em sete dias. Desses sete dias, seis são destinados ao trabalho, e o sétimo, ao descanso. Já que a escola está fechada no dia de descanso, vai-se à igreja. Este texto é seguido de inúmeras perguntas sobre quantos dias tem um ano, qual o primeiro mês do ano e assim por diante, e o bonito exercício de perguntas e respostas esgota-se na duplicação morta. Todos esses cadernos marcam essa regularidade, que se mantém forte até o presente, que é a lidação com o tempo a partir de sua contagem cronológica, pautado pela ideia de desenvolvimento e de futuro.

Na década de 1940, temos a emergência de um enunciado nessa contagem cronológica do tempo que até então não havia aparecido nos cadernos examinados: "Aproveitar o tempo", título de um texto. O texto narra uma professora que irá premiar a aluna com as melhores notas. A criança diz à mãe o que será dela se faltar-lhe a memória. A mãe responde-lhe que basta que acorde cedo e estude bastante, basta que "aproveite o tempo". Falamos aqui da emergência de certa relação utilitária com o tempo, em prol da produtividade escolar.

Nas décadas de 1950 e 1960, evidenciam-se muitos registros com descrição cronológica do tempo, descrição das estações do ano, desenhos de relógios e contas matemáticas para calcular o tempo, descrição das estações do ano, do movimento de rotação e translação da Terra, fases da lua, sendo que a hora da missa aparece regularmente. Juntamente a isso, vai se fortalecendo o enunciado do tempo produtivo, marcado pela ideia de futuro.

Em muitos cadernos, aparecerá a fábula de Esopo reconstruída por La 
Fontaine "A cigarra e a formiga", na qual a cigarra é punida por passar o verão cantando, enquanto a formiga trabalhava. Podemos pensar que a preguiça, como valor, assume na sociedade disciplinar um "[...] caráter de negligência e inutilidade, o qual deve ser corrigido; que na filosofia kantiana assume lugar de fraqueza que nos impede de alcançarmos certa autonomia; que na sociedade contemporânea de produção é assumida como um empecílio para certo sucesso e consumo". (SCHULER, 2014, p. 110).

Já em um caderno de 1973 , uma menina da $2^{\mathrm{a}}$ série completa uma atividade que solicitava "Escrever, nos quadrinhos, alguma coisa que fazes". O quadrinho é dividido em manhã e noite. A menina descreve que toma seu tempo com estudo, brincadeira, alimentação, sono e televisão. Já em 1995, aparece descrita uma infância que vai ser alguma coisa, como promessa de futuro, sendo a relação com o tempo fortemente pautada pelo futuro (esse é enunciado bastante regular nos cadernos examinados).

Figura 3: Você acredita no futuro?

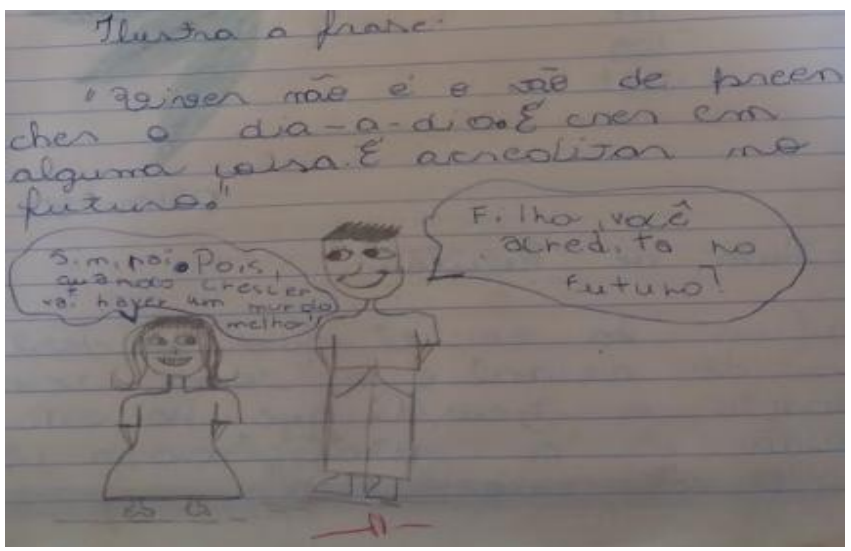

Fonte: Hisales (Caderno de 1995)

Nesse mesmo caderno, aparece um texto fotocopiado intitulado "Os tempos da vovó”. Esse texto descreve uma menina que brinca de ser mãe de suas bonecas, que cresce e tem sua boneca de verdade e que no futuro será ainda mais feliz com a chegada dos netos, sendo que todos os tempos da vida 
dela estão guardados no coração "ontem, hoje, amanhã". O tempo aparece atravessando o feminino e a obrigatoriedade da maternidade como o que marca a passagem do tempo para as mulheres. Já os cadernos recolhidos em 2016, na região metropolitana de Porto Alegre e na serra gaúcha, narram toda essa contagem cronológica do tempo, mas com uma preocupação muito contemporânea das crianças em relação à produtividade do tempo, agora fortemente atravessada pela aceleração.

Figura 4: Acabou o tempo

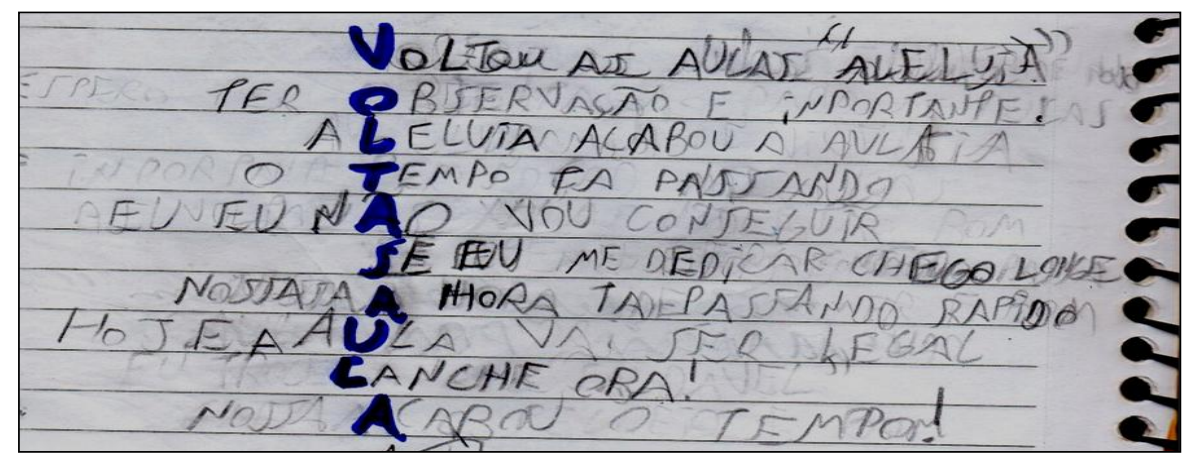

Fonte: Caderno recolhido em escola Municipal de Ensino Fundamental na serra gaúcha em 2016.

Figura 5: Então ele aproveitou toda a vida dele

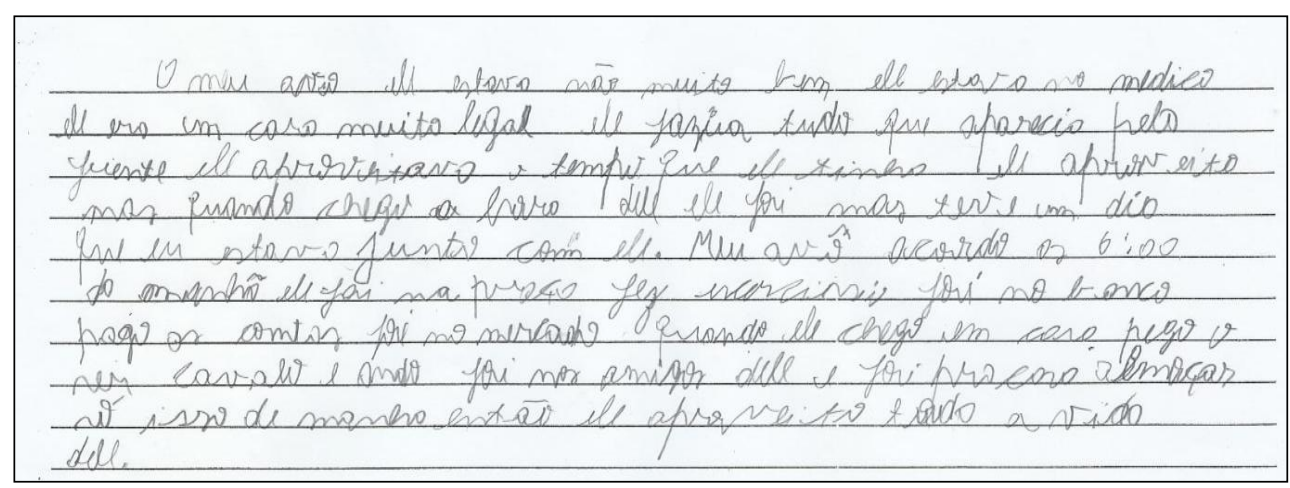

Fonte: Caderno recolhido em escola Municipal de Ensino Fundamental na serra gaúcha em 2016.

Nesse sentido, mantém-se o enunciado da infância como promessa de 
futuro, mas agora mais fortemente marcando a velhice como inutilidade, por não poder mais trabalhar. A velhice é narrada no passado e, portanto, nessa maquinaria capitalística, operada como desvalor. O lugar da memória e da tradição são ocupados pela utilidade capitalística e pela velocidade das informações nos meios digitais, operando na lógica moderna de construir-se negando o passado e aspirando à inovação e à ruptura, mas agora com a marca da aceleração.

Observa-se uma preocupação fortemente pontuada em ganhar tempo, aproveitar o tempo ou fazer passar o tempo para ser algo ou alguém, ainda no mesmo regime de verdade que coloca as crianças em uma dimensão de falta e de futuro. Uma relação com o tempo em uma vida mecânica, subtraída a experiência, com a correria nas grandes cidades, nessa "pacífica existência cotidiana”, em que se volta para casa no final do dia esgotado de tantos eventos, mas nada se torna experiência, sendo talvez a insuportabilidade contemporânea de nossas vidas. (AGAMBEN, 2005).

O poder disciplinar, pois, produziu práticas de escrita e leitura que atravessam os corpos, produzindo-os como aptidões. A sociedade do desempenho vem atravessando as infâncias com a preocupação de ocuparem o tempo de forma produtiva a fim de "serem alguém no futuro", por meio de práticas de escrita e de leitura marcadas pelo desenvolvimento de habilidades e competências, preocupadas com o ensino de saberes úteis, rapidamente aplicáveis, que atendam aos interesses individuais das crianças. Desse modo, “o sujeito do desempenho, esgotado, depressivo, está, de certo modo, desgastado consigo mesmo. Está cansado, esgotado de si mesmo, de lutar consigo mesmo. Totalmente incapaz de sair de si, de estar lá fora, de confiar no outro, no mundo, fica se remoendo, o que paradoxalmente acaba levando à autoerosão e ao esvaziamento" (HAN, 2017, p. 90).

Assim, nada dura o suficiente para que algo se passe. O instante é operado apenas como aquele que divide o passado e o presente. Mas não seria a escola ainda esse local onde se transmitem aos recém-chegados os modos de 
pensar e de viver, os valores e tudo mais? Se tomarmos a escola por esse sentido clássico de tempo livre e de um lugar onde se conversa com os vivos e os mortos, poderemos entender que aquilo que aconteceu não está no passado - continua existindo e produzindo efeitos. Dessa forma, “[...] o que é a esperança, o desejo, a memória, a imaginação, senão formas de dar conta daquilo que, sem estar plenamente presente, atua vivamente sobre nosso modo de pensar, sentir e agir?” (LÓPEZ, 2015, p. 147). O que seria de nós, nestes tempos de ódio em que vivemos, sem esperança, desejo, memória e imaginação? Por isso, as práticas de leitura e escrita na escola poderiam ser tomadas menos na ordem das habilidades e competências e mais como formas possíveis de trazer algo ao mundo, de fazer nascer algo.

A partir dessa relação com o tempo marcada pela necessidade de muitos exercícios, de atividades definidas por habilidades técnicas que operam com a língua escrita como decifração de um código e da contagem cronológica e produtiva do tempo, em que a infância é narrada como dimensão de falta, poderíamos inverter a própria valoração da falta por meio do Artista da Fome de Kafka (2011). Infância como falta, não como algo que deve se tornar ou ser completado, preenchido ou abarrotado. Quando valoramos a falta pela minoração kafkiana (DELEUZE, GUATTARI, 2002), podemos tomar a infância como falta, operando a falta como potência, como aquilo que abre espaço, que deixa brecha, que não entope tudo, que não se satisfaz com tudo. No dicionário etimológico, a palavra falta é seguida da palavra falua, um tipo de embarcação antiga. (CUNHA, 2010). Aquilo que nos arrasta, que faz viajar, que deixa espaço para dizer de outra língua, de outra infância e de outro tempo.

Assim, falta como potência e como algo atravessando a infância poderia ser tomada para se pensar nas relações com o tempo? Para se pensar na necessidade de uma atenção? Para se pensar em um tipo de escuta com um mundo que opera outra política, outra linguagem, que questiona o espaço comum em que as palavras e as coisas supostamente se encontrariam e que questiona a continuidade, a comunicação e a reflexão? Outra escrita? Outra 
leitura?

Recorrendo à etimologia novamente, é interessante pensar que o verbete ler é seguido do verbete lerdo. Agrada-me esse arranjamento livresco que constrói uma série. Porque quem lê, quem lê estudando ao menos, tem sempre alguma coisa de lerdo. Ou deveria ter. No dicionário, a lerdeza continua a leitura. No dicionário, o lerdo é aquele "pesado, estúpido, acanhado, lento nos movimentos" (CUNHA, 2010, p. 386). Agamben (2016) já dizia que quem estuda tem um quê de estupefação e estupidez. Ler estudando, então, impregnaria um ritmo de estudo.

E se tomássemos as práticas de escrita e leitura na escola pautadas por outra relação com o tempo, mais atento consigo e com o mundo, que ao invés de pensar em eventos em sequência nas nossas vidas a serem descritos, ao invés de contar o tempo e tentar torná-lo produtivo em prol de um futuro prometido, afinássemos nosso olhar para prestarmos atenção ao que estamos nos tornando no presente? E se apostássemos na necessidade de intervalos? Talvez essas questões abram para uma relação mais filosófica com a escrita e a leitura, no sentido de uma experiência vivida, que operaria com os problemas não como o outro do pensamento, mas justamente como aquilo que dá sentido ao exercício. Daí a inseparabilidade da oralidade, da escrita, da leitura, de perguntas, de respostas e da conversação, quando tomamos como inspiração algumas práticas da antiguidade (HADOT, 2016). Tal inspiração no cuidado de si poderia ser potente para tomarmos a escola vinculada à certa necessidade de atenção, à certa escuta e, portanto, à certa relação com o tempo.

Por isso, este artigo coloca-se como um manifesto por uma necessidade de pensar em meio a tantos exercícios de escrita positiva, de dar existência para coisas ainda não pensadas, ditas, escritas, lidas, o que exige o intervalo. Um manifesto pelas práticas de escrita e leitura na escola que operem com as acelerações, mas também com as pausas e intervalos, problematizando nossas relações servis com nós mesmos, que passam pelas relações servis com esse tempo mecânico e repetitivo. 
Devemos então supor que se introduzimos um intervalo de tempo entre a ação e a reação, entre a causa e o efeito, entre o imperativo e a resposta, se introduzimos a duração de uma hesitação, estaremos introduzindo no mundo uma certa porção de liberdade? Essa diferença de ritmo não é a própria liberdade? (LAPOUJADE, 2017, p. 24).

Por isso poderíamos desconfiar quando a única legitimidade imaginável é a aceleração, o conhecimento verificável na escola, o texto confortável, as respostas automáticas, pois estamos produzindo um mundo fechado para a criação de outros sentidos e modos de vida. Isso passa, neste manifesto, pela problematização das práticas de linguagem na escola e pelas relações com o tempo. Uma vez que "[...] o tempo se dá, de maneira privilegiada a minha experiência em atividades de linguagem - no canto, na recitação, na escrita, na fala - só consigo falar, escrever, cantar e contar porque posso lembrar, exercer minha atenção e prever" (GAGNEBIN apud LEITE, 2011, p. 113-114).

Talvez nossos combates no presente circulem na luta contra os diversos modos de fascismo e talvez, junto com isso, porque se tratam de coisas vizinhas, uma luta que problematiza a aceleração, o utilitarismo curricular e a não escuta da vida. Isso porque não se quer entreter as crianças ou fazer passar seu tempo, mas preocupar-se com a sua formação. Todavia, parece-me que os discursos educacionais inovadores no presente, esses do desempenho, estão preocupados em atender aos "interesses" das crianças, em não cansar sua paciência. Optam pela quantidade excessiva de atividades, que cresceu consideravelmente no último século. Trata-se, parece-me, de alimentar diariamente as crianças com muita comida, mas não se pergunta qual comida, por que esta e não outra, e, principalmente, quais os efeitos digestivos. Comer com pressa não faz bem. Qual a força combativa dos textos usados com as crianças?

Quando se trata da pergunta pela escrita e leitura na escola em suas relações com a infância e o tempo, está se perguntando pelos regimes de verdade no presente, pelos modos de governo e também pelas relações que estabelecemos com nós mesmos. Por isso, não se trata apenas do que os alunos 
e alunas sabem dos textos, mas do que estão se tornando a partir deles, como estão sendo atravessados, como estão vivendo essa relação. Essa perspectiva pode ser desesperadora pelos obcecados pela quantificação e medição, pelo desenvolvimento das crianças para serem o futuro da grande nação brasileira, com foco nas informações e no desempenho. $\mathrm{O}$ valor da escrita e da leitura, como e o que se lê e se escreve no presente, traz as marcas de um humano valorado em termos de produtividade, e, nessa perspectiva, fala-se sempre em um tempo por vir, em uma lógica de progresso, como que excluindo a potência do instante. Nesse espaço público das salas de aula, onde podemos pensar com o outro sem necessariamente pensar o mesmo, como podemos ampliar a preocupação em fazer lidação com saberes úteis para exercitar o pensamento, trazendo outras intensidades para nossas vidas, privilegiando o instante?

No tempo sucessivo (chrónos), o instante se torna uma maldição. Num tempo que se pensa como extensão, o instante não cabe no tempo, ele passa tão depressa que jamais conseguiremos habitá-lo. Por isso, o tempo cronológico é o tempo da postergação e da espera [...]. A cultura ocidental tem privilegiado essa visão do tempo e no mundo moderno e contemporâneo ela tem sido pensada sob a forma de progresso. A escola como instituição moderna tem adotado sua forma. Um tempo linear, sucessível, irreversível, que serve como parâmetro para medir a atividade. Um tempo de fabricação. (LÓPEZ, 2008, p. 99).

Por isso um manifesto lento. Leitura e escrita como escolha, como recolhimento, como cuidado, como memória, como tempo sensível, como possibilidade de inauguração de outras possibilidades de lidação com o mundo e consigo em experiências coletivas e singulares em salas de aula que podem ser um testemunho que estranhe o mais familiar: nossas relações com o tempo. Ler e escrever não para ser aplaudido, avaliado, entupir-se de informações ou para dar opinião. Mas ler e escrever também para fazer silêncio; como um manifesto do inútil; como composição de uma atenção com os modos de subjetivação; como conversação, estudo e formação; como concentrar-se em si, no instante, estando com o outro; como uma relação mais psicagógica na escola, que 
atravesse os modos de existência (FOUCAULT, 2011). Ler e escrever como um nutrir-se, justamente para ter forças para colocar-se de pé diante de si e puxarse para fora.

\section{AINDA ALGUMAS IMPORTÂNCIAS}

Foi tomado o funcionamento das escritas das crianças em suas relações com o tempo para pensar como dão também forma para essas existências. A partir disso, evidenciei o deslocamento de uma relação nessas práticas de escrita e leitura que pensam a vida e a morte e que se deslocam para uma contagem cronológica do tempo, sendo a infância promessa de futuro em uma lidação de aceleração e produtivismo com o tempo. Uma relação mercantil que produz uma existência agitada e apartada de si e dos demais, que valora primeiramente o útil e denuncia a velhice como sem importância.

Poderia essa escola contemporânea do desempenho, das competências, da superaceleração, ainda funcionar como formação, como certo deslocamento de si? Poderia, ainda, pensar sobre a vida, o tempo, a morte, em brechas e resistindo ao que estamos nos tornando? Poderia, ainda, ensinar outros modos de viver e de morrer? Poderia, ainda, picar os alunos como tavões 5 esfomeados por carne humana? E poderiam esses corpos ter força para movimentarem-se em outras direções? Poderia, ainda, a escola parir filhos estrangeiros de si mesma? E como perguntar isso sem falar na escola "em geral", sem perguntar de uma forma retórica, mas cheia de gosto?

Desse modo, o menor de Kafka também passa por uma outra relação com o tempo, que não está dada de antemão, pois precisa ser inventada. Por isso o macaco relatoriador (KAFKA, 2009) preferiu a existência por saídas e

\footnotetext{
5 Foucault (2011, p. 9), discutindo o conceito de cuidado de si em Sócrates, compara-o a um tavão, um inseto que persegue os animais e os pica, causando desconforto e movimento, uma vez que "o cuidado de si é uma espécie de aguilhão que deve ser implantado na carne dos homens, cravado na sua existência, e constitui [...] um princípio de permanente inquietude no curso da existência".
} 
entradas múltiplas à busca pela promessa de liberdade - e, nessas invenções, outras possibilidades de vida e pensamento. Em tempos de elogio às armas em punho, este manifesto prefere ficar com o elogio aos livros, à escrita e à leitura feitas no coletivo das salas de aula que ainda resistem. Resistem ensinando palavras sábias que podemos encontrar nos textos desse e em outros tempos e perspectivas, compartilhando boas companhias, disparando outras possibilidades, sem controle de seus efeitos, perguntando se a educação escolar ainda pode estar vinculada à atenção do cuidado de si.

Ordine (2016), a partir de Sócrates, diz que homens livres não tem problemas com o tempo. Talvez melhor do que a palavra liberdade, poderia dizer que homens inventores de entradas e saídas, homens que necessitam respirar à aceleração, ao produtivismo e ao utilitarismo inventam com outros pesos. E o fazem não tanto pela denúncia, pois estão profundamente ocupados com a vida, com o instante, como uma relação infantil com o tempo.

\section{REFERÊNCIAS}

AGAMBEN, Giorgio. Infância e história: ensaio sobre a destruição da experiência. In: AGAMBEN, Giorgio. Infância e história: destruição da experiência e origem da história. Trad. de Henrique Burigo. Belo Horizonte: Editora UFMG, 2005, p. 19-78.

AGAMBEN, Giorgio. Ideia do estudo. In: AGAMBEN, Giorgio. Ideia de prosa. $2^{\mathrm{O}}$ reimp. Trad. de João Barrento. Belo Horizonte: Autêntica, 2016, p. 52-55.

BENJAMIN, Walter. Experiência e pobreza. In: BENJAMIN, Walter. Magia e técnica, arte e política: ensaios sobre literatura e historia da cultura. Trad. de Sérgio P. Rouanet. $8^{\circ}$ ed. São Paulo: Brasiliense, 2012, p. 123-128. (Obras Escolhidas v. 1).

COSTA, Luciano Bedin da. Ainda escrever: 58 combates para uma política do Texto. São Paulo: Lumme Editor, 2017.

CUNHA, Antônio Geraldo da. Dicionário Etimológico da língua portuguesa. $4^{\circ}$ ed. Rio de Janeiro: Lexikon, 2010. 
DELEUZE, Gilles. Post-scriptum sobre as sociedades de controle. In:

DELEUZE, Gilles. Conversações. 1972-1990. Trad. de Peter Pál Pelbart. Rio de Janeiro: 34, 2008, p. 219-226.

DELEUZE, Gilles, GUATTARI, Félix. Kafka: para uma literatura menor. Trad. de Rafael Godinho. Lisboa: Assírio \& Alvim, 2002.

DIDI-HUBERMAN, Georges. Sobrevivência dos vaga-lumes. Trad. de Vera C. Nova e Márcia Arbex. Belo Horizonte: Editora UFMG, 2014.

DULLIUS, Rodrigo. A emergência do aluno trabalhador no Brasil no contexto do Proeja. Tese de Doutorado (Doutorado em Educação). PPGEDU. Universidade do Vale do Rio dos Sinos, UNISINOS. São Leopoldo, 2019.

FOUCAULT, Michel. Arqueologia do Saber. $6^{\circ}$ ed. Trad. de Luiz F. B. Neves. Rio de Janeiro: Forense Universitária, 2002a.

FOUCAULT, Michel. Vigiar e punir: nascimento da prisão. Trad. de Raquel Ramalhete. $25^{\circ}$ ed. Petrópolis: Vozes, 2002b.

FOUCAULT, Michel. Nietzsche, a genealogia e a história. IN: FOUCAULT, Michel. Microfísica do Poder. $10^{\circ}$ ed. Traduzido por Roberto Machado. Rio de Janeiro: Graal, 2003, p. 15-37.

FOUCAULT, Michel. A Hermenêutica do Sujeito: curso dado no Collège de France (1981-1982). Ed. de François Ewald, Alessandro Fontana, Fréderic Gros. Trad. de Marcio A. da Fonseca, Salma T. Muchail. $3^{0}$ ed. São Paulo, Martins Fontes, 2011.

GRAZZIOTIN, Luciane Sgarbi S. Páginas que persistem: cadernos de ciências naturais e a permanência de um tempo escolar (1940/1960). In: Maria Helena Camara Bastos, Alice Rigoni Jacques, Doris Bittencourt Almeida. (Org.). Do Deutscher Hilfsverein ao Colégio Farroupilha/RS: memórias e histórias (1858-2008): volume II. $1^{0}$ ed. Porto Alegre: EDIPUCRS, 2015, v. 2, p. 170-186.

HADOT, Pierre. A filosofia como maneira de viver: entrevistas de Jeannie Carlier e Arnould I. Davidoson. Trad. de Lara C. de Malimpensa. São Paulo: É Realizações, 2016.

HAN, Byung-Chul. Sociedade do Cansaço. Trad. de Enio P. Giachini. Petrópolis: Vozes, 2015.

KAFKA, Franz. A toca. Trad. de Franciso Agarez. Lisboa: LxXL Edições, 2009.

KAFKA, Franz. Um artista da fome. In: KAFKA, Franz. Essencial. São Paulo: Penguim Classics Companhia das Letras. Trad. e Seleção de Modesto Carone, 
2011.

LAPOUJADE, David. Potências do tempo. Trad. de Hortência S. Lencastre. São Paulo: n-1 Edições, 2017.

LEITE, César D. P. Infância, experiência e tempo. São Paulo: Cultura Acadêmica, 2011.

LERMEN, Sabrina, SCHULER, Betina. Filosofia com crianças na escola: práticas de leitura, escrita e exercício do pensamento na problematização do tempo. Holos, IFRN, Natal, v. 02, ano 34, p. 289-306, 2018.

LÓPEZ, Maximilano V. Habitar poeticamente a educação: notas sobre a relação entre potência e temporalidade. Educ. Foco, Juiz de Fora, v. 20, n. 1, p. 141158, mar./jun. 2015.

NIETZSCHE, Friedrich. A Gaia Ciência. $5^{\circ}$ reimpressão. Trad. de Paulo C. de Souza. São Paulo: Companhia das Letras, 2009.

Ó, Jorge Ramos do. O governo de si mesmo: modernidade pedagógica e encenações disciplinares do aluno liceal (último quartel do século XIX - meados do século XX). Lisboa: Educa e Autor, 2003 (Coleção Educa - Ciências Sociais, $\left.n^{0} 2\right)$.

ORDINE, Nuccio. A utilidade do inútil: um manifesto. Trad. de Luiz C. Bombassaro. Rio de Janeiro: Zahar, 2016.

PAGNI, Pedro. Um ensaio sobre a experiência, a infância do pensamento e a ética do cuidado: pensar a diferença e a alteridade na práxis educativa. In: KOHAN, Walter O. (Org.). Devir-criança da filosofỉa: infância da educação. Belo Horizonte: Autêntica, 2010, p. 63-79.

SCHULER, Betina. Por entre escritas, leituras e cadeiras: o procedimento genealógico e o cuidado de si. In: SCHULER, B.; MATOS; S. R. L.; CORAZZA, S. M. (Orgs.) Caderno de notas 6: experimentações de escrita, leitura e imagem na escola. Porto Alegre, RS: UFRGS/DOISA, 2014, p. 69-128.

SCHULER, Betina. Escrita escolar, ficção e modos de subjetivação. Educação Unisinos, São Leopoldo, 21 (2), p. 231-240, mai./ago., 2017.

SÊNECA, Lúcio Anneo. Do ler e do escrever. In: SÊNECA, Lúcio Anneo.

Aprendendo a viver: cartas a Lucílio. Trad. de Lúcia S. Rebello e Ellen I. N. Vranas. Porto Alegre, L\&PM, 2011a, 137 p. 80-83.

SÊNECA, Lúcio Anneo. Sobre a brevidade da vida. Trad. de Lúcia S. Rebello, Ellen I. N. Vranas e Gabriel N. Macedo. Porto Alegre, L\&PM, 2011b. 
SEIBERT, Mônica. Uma perspectiva trágica do sofrimento nas práticas escolares. Dissertação de Mestrado (Educação). PPGEDU. Universidade do Vale do Rio dos Sinos, UNISINOS. São Leopoldo, 2019.

SIBILIA, Paula. Redes ou Paredes: a escola em tempos de dispersão. Trad. de Vera Ribeiro. Rio de Janeiro: Contraponto, 2016.

VEIGA-NETO, Alfredo. Espaços, tempos e disciplinas: as crianças ainda devem ir à escola?. In: Vera Maria Candau. (Org.). Linguagens, espaços e tempos no ensinar e aprender. Rio de Janeiro (RJ): DP\&A, 2000, p. 9-20.

BETINA SCHULER é pedagoga (UNISC); Mestre e Doutora em Educação (PUCRS); Pós-Doutora em Educação (Universidade de Lisboa/Portugal); PósDoutora em Ciências Humanas (Griffith University, Austrália). Professora no Programa de Pós-Graduação em Educação na Universidade do Vale do Rio dos Sinos.

E-mail: betinaschuler@hotmail.com

(D) http://orcid.org/ 0000-0002-2424-7601

Recebido em: 18 de janeiro de 2019

Aprovado em: 01 de julho de 2019 